\title{
Fooling the brain to alleviate dyspnoea
}

\author{
Capucine Morélot-Panzini ${ }^{1,2}$
}

Affiliations: 'Sorbonne Universités, UPMC Université Paris 06, INSERM, UMRS_1158, Neurophysiologie respiratoire expérimentale et clinique, Paris, France. ${ }^{2}$ Assistance Publique-Hôpitaux de Paris (AP-HP), Groupe Hospitalier Pitié-Salpêtrière Charles Foix. Service de Pneumologie et Réanimation Médicale, (Département “R3S"), Paris, France.

Correspondence: Capucine Morélot-Panzini, Service de Pneumologie et Réanimation Médicale (Département "R3S") Groupe Hospitalier Pitié-Salpêtrière Charles Foix, 47-83 Bd de l'Hôpital, 75651 Paris Cedex 13, France. E-mail: capucine.morelotapsl.aphp.fr

@ERSpublications

The application of a stream of air onto the face by a hand-held fan has a real place in the treatment of dyspnoea http://ow.ly/tKJk30dJ5Pv

Cite this article as: Morélot-Panzini C. Fooling the brain to alleviate dyspnoea. Eur Respir J 2017; 50: 1701383 [https://doi.org/10.1183/13993003.01383-2017].

Dyspnoea affects a multitude of patients with a multitude of diseases, and therefore concerns a multitude of physicians and other healthcare professionals. In view of the physical and psychological distress associated with dyspnoea, and in view of the pervasive impact of dyspnoea on the patient's psychological state and social life $[1,2]$, relieving dyspnoea should constitute a leading and universal clinical goal. Some have even proposed that failing to provide a patient with dyspnoea with "state of the art" management of this symptom would constitute an infringement of human rights $[3,4]$.

However, dyspnoea can be particularly difficult to relieve. Correction of the respiratory abnormalities responsible for dyspnoea is not always possible or only partially so. So-called pathophysiological treatments can therefore fail to satisfactorily relieve the patient's suffering. In these settings, whether persistent dyspnoea is "chronic" (chronic breathlessness syndrome) [5] or acute [6], it is essential to implement alternative measures. The efficacy of these measures is affected by the multidimensional nature of dyspnoea, which involves sensory perception, cognition and emotion, allowing a large range of therapeutic approaches. This strategy to care for dyspnoea is not an idea or a concept worth considering: it is state of the art, as illustrated by explicit recommendations in certain guidelines (for example, the 2017 edition of the Global Initiative for Chronic Obstructive Lung Disease statement indicates that "all clinicians managing patients with [chronic obstructive pulmonary disease] should be aware of the effectiveness of palliative approaches to symptom control and use these in their practice" [7]).

To relieve dyspnoea when pathophysiological treatments are not sufficient, various pharmacological approaches are available, such as the administration of opiates [4, 8], or under investigation [9]. Nonpharmacological approaches are also under investigation, and are designed either to modify brain processing of signals from the respiratory afferent nerves [10] or to modify psychological and emotional management [11]. Another way to address this issue consists of "fooling the brain", "to make it believe" that the respiratory system functions better than it actually does. The relieving effect of applying a stream of air onto the face, as described in the study by LUCKETT et al. [12] published in this issue of the European Respiratory Journal, may derive from this principle.

The possibility of relieving dyspnoea by deceiving the brain about the real performance of the respiratory system was first demonstrated in the 1950s. In a groundbreaking study published in the Journal of Applied Physiology in 1954, Fowler [13] showed that subjects who had held their breath to the breaking point of a

Received: July 102017 | Accepted: July 112017

Conflict of interest: Disclosures can be found alongside this article at erj.ersjournals.com

Copyright @ERS 2017 
voluntary apnoea (intolerable respiratory discomfort) were able to resume apnoea after having taken several breaths of a hypoxic and hypercapnic gas mixture, an action that failed to correct gas exchange. This meant that they had experienced relief in spite of the persistence of the problem that had generated their distress and led them to break the breath-holding. This phenomenon can be interpreted as resulting from the stimulation of stretch receptors by the hypoxic-hypercapnic respiratory movements, a stimulation that is known to attenuate dyspnoea. It is compatible with sensory-motor re-equilibration, in line with the currently prevailing theory that makes the balance between ventilatory drive and respiratory afferents a major determinant of dyspnoea [2]. According to this model, the brains of the participants in the experiment could have (wrongly) "anticipated" resolution of the abnormality responsible for dyspnoea upon perceiving the afferent messages generated by respiratory movements: dyspnoea relief occurred despite the absence of correction of gas exchange. This is essentially the same hypothesis as that called upon to explain relief of dyspnoea by inhalation of furosemide, which is known to induce pharmacological stimulation of slowly adapting pulmonary stretch receptors [14]. Inhaled furosemide can relieve experimental $[15,16]$ and clinical dyspnoea $[17,18]$.

In this context, the effect of a stream of cold air onto the face on dyspnoea has been studied since the 1980s. A study conducted in healthy subjects showed that application of cold air to the face by a fan modifies the perception of experimental dyspnoea without modifying ventilation or respiratory drive, while application of cold air to the leg had no effect [19]. More recently, the use of a fan to project air onto the face (at room temperature) has been shown to relieve dyspnoea patients meeting the definition of "chronic breathlessness" $[20,21]$. The use of a hand-held fan to relieve dyspnoea is now an integral part of the Breathlessness Support Service, a "care bundle" with demonstrated benefits now proposed in the UK [22, 23].

The study by LuCKETT et al. [12] describes the perception that patients and their caregivers have of the benefits of a hand-held fan. It also describes the practical use of this fan based on qualitative analysis of semidirected interviews conducted in 133 patients and 72 caregivers in three randomised trials designed to evaluate various nonpharmacological treatments for chronic (or persistent) breathlessness. The first trial (Breathlessness Intervention Service; 111 patients) [24-27] studied a new management strategy for dyspnoea that included the use of a hand-held fan. The second study (Calming Hand and Fan Feasibility; 11 patients) (not published to date) evaluated the benefit of a fan either alone or associated with a relaxation session. The third study (Fan, Activity, Breathlessness; 11 patients) [28] evaluated application of a high- or low-frequency fan. Overall, the fan was considered to be beneficial by $72 \%$ of patients and substantially beneficial by $10 \%$ of patients. The greatest benefit was observed in the youngest patients (under the age of 70 years) and in cancer patients. The beneficial effect consisted of a reduction of dyspnoea recovery time more than a reduction of the intensity of dyspnoea. Patients appeared to appreciate the efficacy of the fan, which gave an impression of facilitated inspiration. In some patients, use of the fan allowed a reduction of $\beta_{2}$-mimetic or medical oxygen consumption. Patients used the fan for an average of 4-5 min. The main concerns expressed by patients were technical problems related to the battery or the robustness of the fan, practical problems (especially related to the absence of freedom of hand movements), the fear of projection of dust into the eyes or airways, and the fear of what other people might think. The authors acknowledge that their study has a number of limitations, which they describe in detail. An additional limitation is that the study does not provide any really new knowledge on either the clinical effects or the mechanisms responsible. Nevertheless, it provides a new and important overview of this therapeutic approach; namely, the point of view of the patients. It seems safe to say that this study provides additional reasons to promote the more widespread use of fans in the symptomatic management of dyspnoea: it is an effective, easy-to-use technique that has no adverse effects.

The mechanisms responsible for the positive effect of a fan on dyspnoea have yet to be determined. Various hypotheses, which may not be mutually exclusive, could be envisaged. This effect could be due to a simple "distraction" effect. It could also be related to an "empowerment" effect. A mechanism analogous to the gate control phenomenon described for pain can also be proposed but is unlikely because of the highly "metameric" nature of this phenomenon: the territory stimulated by the stream of air would need to be the main source of dyspnoea-related afferents, which is unlikely. Another hypothesis would be that stimulation of trigeminal nerve facial receptors "fools" the brain into believing that ventilatory flow is higher than it really is, in the wake of the concepts derived from the study by FowLER [13] and the furosemide studies (see earlier). The effects of the fan can be considered in the light of data demonstrating the equivalent benefit of nasal administration of oxygen or dry air on persistent dyspnoea in palliative care patients [29] and data showing the benefit of L-menthol inhalation on experimental dyspnoea [30, 31]. This effect would be mediated by stimulation of cold-sensitive TRPM8 channels present on neurons of the trigeminal nerve and vagal afferents [31].

Whatever the mechanisms at play, in the light of the data in the previous literature and the article by LUCKETT et al. [12], it is possible to confirm that application of a stream of air onto the face by means of a 
hand-held fan has a real place in the management of some forms of dyspnoea. Failure to take this concept into account in clinical practice would mean failing to comply with the implicit and explicit $[3,4,7]$ principles that should govern the management of dyspnoea in medicine.

\section{References}

1 Lansing RW, Gracely RH, Banzett RB. The multiple dimensions of dyspnea: review and hypotheses. Respir Physiol Neurobiol 2009; 167: 53-60.

2 Parshall MB, Schwartzstein RM, Adams L, et al. An official American Thoracic Society statement: update on the mechanisms, assessment, and management of dyspnea. Am J Respir Crit Care Med 2012; 185: 435-452.

3 Basoglu M. Effective management of breathlessness: a review of potential human rights issues. Eur Respir J 2017; 49: 1602099 .

4 Currow DC, Abernethy AP, Ko DN. The active identification and management of chronic refractory breathlessness is a human right. Thorax 2014; 69: 393-394.

5 Johnson MJ, Yorke J, Hansen-Flaschen J, et al. Towards an expert consensus to delineate a clinical syndrome of chronic breathlessness. Eur Respir J 2017; 49: 1602277.

6 Morélot-Panzini C, Adler D, Aguilaniu B, et al. Breathlessness despite optimal pathophysiological treatment: on the relevance or not of being chronic. Eur Respir J 2017 [in press https://doi.org/10.1183/13993003.01159-2017].

7 Global Initiative for Chronic Obstructive Lung Disease. Global Strategy for the Diagnosis, Management and Prevention of COPD. 2017. Available from: http://goldcopd.org/

8 Ekstrom M, Bajwah S, Bland JM, et al. One evidence base; three stories: do opioids relieve chronic breathlessness? Thorax 2017 [in press https://doi.org/10.1136/thoraxjnl-2016-209868].

9 Barbetta C, Currow DC, Johnson MJ. Non-opioid medications for the relief of chronic breathlessness: current evidence. Expert Rev Respir Med 2017; 11: 333-341.

10 Nierat MC, Hudson AL, Chaskalovic J, et al. Repetitive transcranial magnetic stimulation over the supplementary motor area modifies breathing pattern in response to inspiratory loading in normal humans. Front Physiol 2015; 6: 273.

11 Williams MT, Cafarella P, Paquet C, et al. Cognitive behavioral therapy for management of dyspnea: a pilot study. Respir Care 2015; 60: 1303-1313.

12 Luckett T, Phillips J, Johnson MJ, et al. Contributions of a hand-held fan to self-management of chronic breathlessness. Eur Respir J 2017; 50: 1700262.

13 Fowler WS. Breaking point of breath-holding. J Appl Physiol 1954; 6: 539-545.

14 Sudo T, Hayashi F, Nishino T. Responses of tracheobronchial receptors to inhaled furosemide in anesthetized rats. Am J Respir Crit Care Med 2000; 162: 971-975.

15 Nishino T, Ide T, Sudo T, et al. Inhaled furosemide greatly alleviates the sensation of experimentally induced dyspnea. Am J Respir Crit Care Med 2000; 161: 1963-1967.

16 Moosavi SH, Binks AP, Lansing RW, et al. Effect of inhaled furosemide on air hunger induced in healthy humans. Respir Physiol Neurobiol 2007; 156: 1-8.

17 Kohara $\mathrm{H}$, Ueoka $\mathrm{H}$, Aoe $\mathrm{K}$, et al. Effect of nebulized furosemide in terminally ill cancer patients with dyspnea. J Pain Symptom Manage 2003; 26: 962-967.

18 Jensen D, Amjadi K, Harris-McAllister V, et al. Mechanisms of dyspnoea relief and improved exercise endurance after furosemide inhalation in COPD. Thorax 2008; 63: 606-613.

19 Schwartzstein RM, Lahive K, Pope A, et al. Cold facial stimulation reduces breathlessness induced in normal subjects. Am Rev Respir Dis 1987; 136: 58-61.

20 Galbraith S, Fagan P, Perkins P, et al. Does the use of a handheld fan improve chronic dyspnea? A randomized, controlled, crossover trial. J Pain Symptom Manage 2010; 39: 831-838.

21 Booth S, Galbraith S, Ryan R, et al. The importance of the feasibility study: Lessons from a study of the hand-held fan used to relieve dyspnea in people who are breathless at rest. Palliat Med 2016; 30: 504-509.

22 Booth S, Ryan R, Spathis A. Service delivery of complex interventions for refractory breathlessness. Curr Opin Support Palliat Care 2016; 10: 228-235.

23 Higginson IJ, Bausewein C, Reilly CC, et al. An integrated palliative and respiratory care service for patients with advanced disease and refractory breathlessness: a randomised controlled trial. Lancet Respir Med 2014; 2: 979-987.

24 Booth S, Farquhar M, Gysels M, et al. The impact of a breathlessness intervention service (BIS) on the lives of patients with intractable dyspnea: a qualitative phase 1 study. Palliat Support Care 2006; 4: 287-293.

25 Farquhar MC, Ewing G, Booth S. Using mixed methods to develop and evaluate complex interventions in palliative care research. Palliat Med 2011; 25: 748-757.

26 Farquhar MC, Prevost AT, McCrone P, et al. Is a specialist breathlessness service more effective and cost-effective for patients with advanced cancer and their carers than standard care? Findings of a mixed- method randomised controlled trial. BMC Med 2014; 12: 194.

27 Farquhar MC, Prevost AT, McCrone P, et al. The clinical and cost effectiveness of a Breathlessness Intervention Service for patients with advanced non-malignant disease and their informal carers: mixed findings of a mixed method randomised controlled trial. Trials 2016; 17: 185

28 Johnson MJ, Booth S, Currow DC, et al. A mixed-methods, randomized, controlled feasibility trial to inform the design of a phase III trial to test the effect of the handheld fan on physical activity and carer anxiety in patients with refractory breathlessness. J Pain Symptom Manage 2016; 51: 807-815.

29 Abernethy AP, McDonald CF, Frith PA, et al. Effect of palliative oxygen versus room air in relief of breathlessness in patients with refractory dyspnoea: a double-blind, randomised controlled trial. Lancet 2010; 376: 784-793.

30 Nishino T, Tagaito Y, Sakurai Y. Nasal inhalation of L-menthol reduces respiratory discomfort associated with loaded breathing. Am J Respir Crit Care Med 1997; 156: 309-313.

31 Kanezaki M, Ebihara S. Effect of the cooling sensation induced by olfactory stimulation by L-menthol on dyspnoea: a pilot study. Eur Respir J 2017; 49: 1601823. 